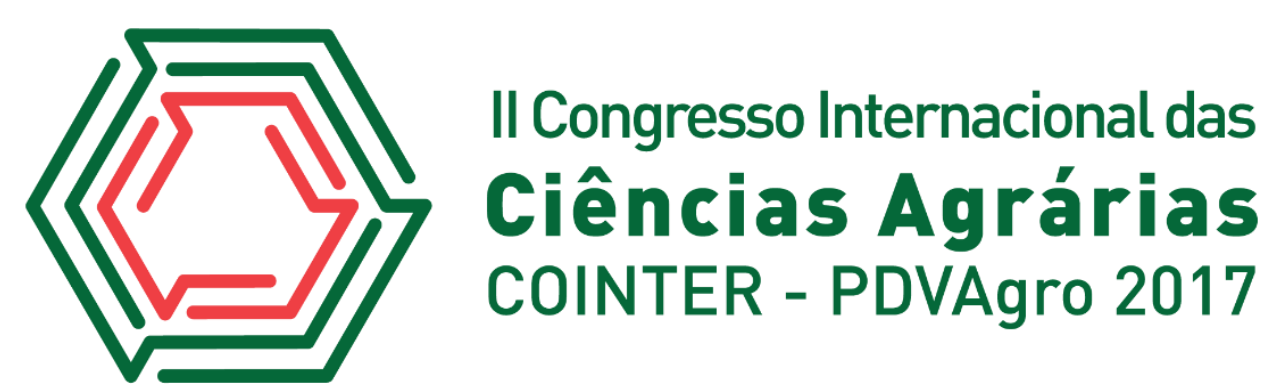

\title{
AVALIAÇÃO DA UNIFORMIDADE EM UM SISTEMA DE IRRIGAÇÃO POR GOTEJAENTO EM CAMPO COM A CULTURA DO MILHO E FAVA
}

\author{
Apresentação: Pôster
}

\begin{abstract}
Valdécio dos Santos Rodrigues ${ }^{1}$; Jonnathan Richeds da Silva Sales²; Emanuel D' Araújo Ribeiro de Ceita ${ }^{2}$; Maria Vanessa Pires de Souza ${ }^{2}$; Geocleber Gomes de Sousa ${ }^{3}$
\end{abstract}

\section{Introdução}

A irrigação é uma prática que traz desenvolvimento para uma determinada região, gerando empregos e com isto reduz o problema de êxodo rural, fazendo com que mais pessoas se fixe no campo e em melhores condições.

A irrigação se torna mais importante ainda na região Nordeste do país, onde a precipitação é baixa e muito irregular, fazendo que se utilize a irrigação na maioria das vezes não como suplementar, mas sim total. É também nessas regiões que se deve atentar para o uso eficiente da água, pois, este recurso é extremamente escasso, e por isso, quanto menos água utilizar para atingir altas produções, melhor.

Agora de nada adianta implantar um sistema de irrigação do mais alto padrão tecnológico, e não se ter a mínima noção de como manejar o sistema, fazendo com que se aplique a água necessária para a planta, isto é, sem excessos e nem déficit, para as culturas.

Os sistemas de irrigação localizada são de grande importância no cenário agrícola brasileiro, com aplicações voltadas principalmente para a fruticultura, horticultura e fertirrigação (MATOS et al., 1999).

A uniformidade de distribuição e o controle da aplicação da água são os dois maiores prérequisitos técnicos para uma ótima irrigação.

Em função das irregularidades da distribuição de água por irrigação localizada, este trabalho tem por objetivo avaliar a uniformidade do sistema de irrigação por gotejamento em uma área cultivada com milho e fava.

\footnotetext{
${ }^{1}$ Mestrando em Engenharia agrícola, Universidade Federal do Ceará, valdeciorodrigues@hotmail.com;

2 Estudante de Agronomia, Universidade da Integração Internacional da Lusofonia Afro-Brasileira, jonnathanagro@gmail.com; emanuelceita@hotmail.com; vanessa.pires1993@gmail.com;

${ }^{3}$ Prof. Doutor, Universidade da Integração Internacional da Lusofonia Afro-Brasileira, sousagg@unilab.edu.br;
} 


\section{Fundamentação Teórica}

Segundo BERNARDO (2002), é de capital importância determinar a uniformidade de distribuição d’água em qualquer método de irrigação e na irrigação por gotejamento é recomendável após a instalação do sistema e a cada dois anos de funcionamento.

Para que a irrigação seja eficiente, é imperativo que os sistemas apresentem alta uniformidade de aplicação da água. Uma vez instalado um projeto de irrigação, é necessário verificar se as condições previstas inicialmente são as mesmas em campo. Para tanto, deve-se avaliar as condições de pressão, vazão e lâminas d'água aplicadas.

Nenhum sistema de irrigação é capaz de aplicar água com perfeita uniformidade. Em geral, o aumento da uniformidade de distribuição da água requer investimentos na melhoria do sistema, em manutenção e em mão-de-obra, para o manejo racional da irrigação (HEERMANN et al., 1992). Por isso, é recomendável, após a instalação de um sistema de irrigação, proceder-se a testes de campo, com o objetivo de se verificar a adequação da irrigação, recomendando, quando necessário, ajustes na operação e, principalmente, no manejo. Esses procedimentos visam maximizar a eficiência (KELLER; BLIESNER, 1990).

Na realidade, a avaliação de sistemas de irrigação é um tema que os agricultores pouco têm dado importância. Mesmo tendo acesso à tecnologia, muitos não a utilizam de forma adequada, por falta de orientação e conhecimento.

Segundo Mantovani et al. (2006), a eficiência de aplicação de água em um sistema de irrigação se resume na diferença entre a quantidade de água que se aplica (sai do equipamento) e a que é efetivamente aproveitada pela planta para seu consumo.

\section{Metodologia}

O experimento foi realizado em Setembro de 2017 na área experimental pertencente a Fazenda da Universidade Internacional da Lusofonia Afro-Brasileira (UNILAB), localizada no Sítio Piroás, pertencente ao município de Redenção, Ceará na região do Maciço de Baturité. A posição geográfica da localidade é: latitude de $04^{\circ} 14^{\prime} 53^{\prime}$ S, longitude de $38^{\circ} 45^{\prime} 10^{\prime}$ W e altitude média de $340 \mathrm{~m}$.

O clima da região é do tipo Aw', sendo caracterizado como tropical chuvoso, muito quente, com chuvas predominantes nas estações do verão e outono (KOPPEN, 1923). A região apresenta precipitação média anual de $1.086 \mathrm{~mm}$, temperatura média do ar de $26^{\circ} \mathrm{C}$ e a umidade relativa média do ar de $71,26 \%$ 
A uniformidade de distribuição de água foi determinada utilizando-se a metodologia proposta por Keller \& Karmeli (1975) onde foram coletadas as vazões em quatro emissores ao longo da linha lateral, da seguinte forma: o primeiro gotejador, o segundo situado a 1/3; o terceiro a 2/3 do comprimento da linha; e o último gotejador.

A água utilizada foi proveniente de uma caixa de água localizada na área experimental e bombeada por uma bomba de $0,5 \mathrm{CV}$ de potência. Os gotejadores possuem uma vazão de $8 \mathrm{~L} / \mathrm{h}$ e são autocompensantes, cujo espaçamento é de $0,5 \mathrm{~m}$ entre gotejadores e 1 metro entre linhas.

Seguindo a metodologia utilizou-se 4 linhas laterais, resultando assim em 16 valores de lâminas e uma disposição de coleta segundo a ilustração na Figura 1.

Utilizou-se um cronômetro e uma proveta volumétrica com capacidade para $200 \mathrm{ml}$, para a coleta da água foram colocados sob os 16 gotejadores recipientes de plástico que acumulavam a água que gotejava, após 1 minuto todos os recipientes eram retirados ao mesmo tempo, e posteriormente era efetuada a medição da quantidade de água acumulada, esse procedimento foi repetido três vezes. Por fim, os volumes coletados foram convertidos para vazão em $\mathrm{L} . \mathrm{h}^{-1}$.

No cálculo do coeficiente de uniformidade de Christiansen (CUC) e de distribuição (CUD), utilizaram-se as seguintes equações:

$$
\begin{aligned}
& C U C=100\left(1-\frac{\sum\left|q_{i}-q^{-}\right|}{n \cdot \bar{q}}\right) \\
& C U D=100 \frac{q_{25 \%}}{\bar{q}}
\end{aligned}
$$

\section{Em que:}

qi = vazão de cada gotejador $\left(L \cdot h^{-1}\right)$,

$\bar{q}=$ vazão média dos gotejadores $\left(\mathrm{L}^{\mathrm{h}} \mathrm{h}^{-1}\right)$,

$\mathrm{n}=$ número de gotejadores,

q25\% = média de $25 \%$ dos menores valores de vazões observadas $\left(\mathrm{L} \cdot \mathrm{h}^{-1}\right)$.

Figura 1. Esquema de coleta de vazões para o teste de uniformidade do sistema de irrigação localizada. 


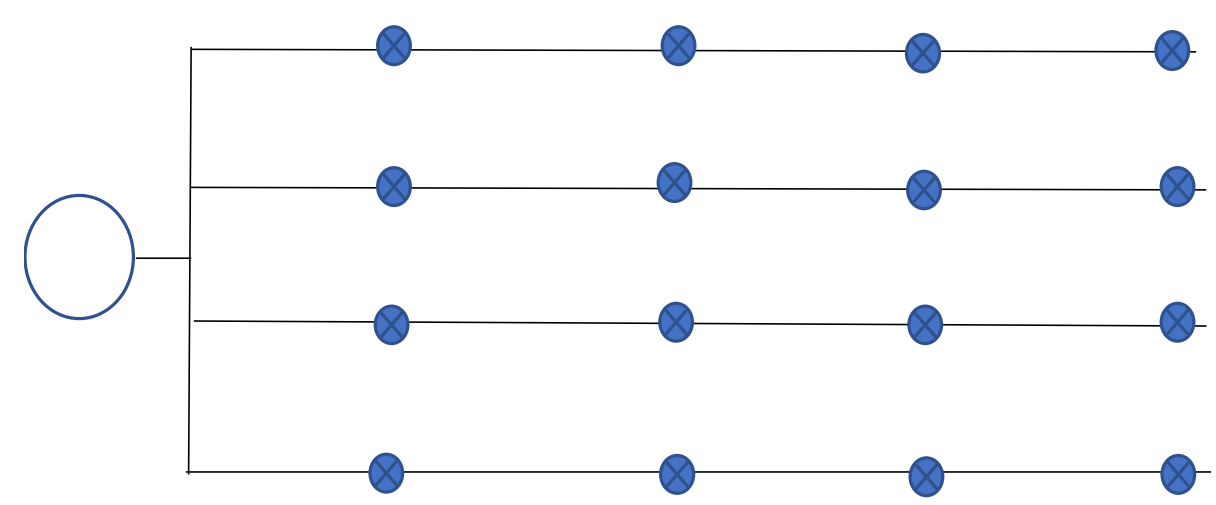

Os cálculos de CUC e CUD foram processados com auxílio de planilhas eletrônicas do Excel.

\section{Resultados e Discussões}

A seguir na tabela 1 são apresentadas as vazões médias das avaliações em cada gotejador e com as médias gerais se obteve os coeficientes de uniformidade.

Tabela 1. Vazão (L/h) medida em cada emissor. Fonte: Própria.

\begin{tabular}{|cccc|}
\hline Linha 1 & Linha 2 & Linha 3 & Linha 4 \\
\hline 8,5 & 8,4 & 8,3 & 8,4 \\
7,8 & 8,3 & 8,8 & 8,3 \\
7,9 & 8,1 & 10,7 & 8,9 \\
8,5 & 8,2 & 8,2 & 8,3 \\
\hline
\end{tabular}

Nota-se uma pequena variação nos valores de vazão calculados, com o valor descrito no catálogo $\left(8 \mathrm{~L} . h^{-1}\right)$, isto pode ser devido a pequenas variações de pressões ao longo da linha lateral.

Tabela 2. Valores de CUC, CUD em \%, obtidos em campo. Fonte: Própria

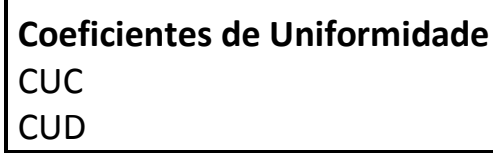

O valor do coeficiente de uniformidade de Christiansen (CUC), segundo Bernardo et al. (2006), está classificado como excelente pois são superiores a 90\%, recomenda-se um valor mínimo admitido de $80 \%$ dentro da parcela de irrigação.

O valor do coeficiente de uniformidade de distribuição (CUD) do sistema de irrigação 
localizada por gotejamento avaliado em campo (Tabela 2) encontra-se classificado como excelente segundo classificação proposta por Keller e Karmeli (1974).

O CUD foi de 93,61\%, sendo menor do que o CUC de 94,05\%. Rezende (1992) afirma que o fato de CUD ser sempre menor que CUC é inerente às variáveis das equações utilizadas na determinação desses coeficientes, pois no cálculo de CUD consideram-se apenas $25 \%$ da área que recebeu menos água. Essas conclusões foram afirmadas por Keller e Bliesner (1990), que considera que o CUD é o mais rigoroso para o dimensionamento e a avaliação em campo de sistema de irrigação, entretanto, este não apresenta uma boa discriminação e logo não identifica de maneira adequada os distúrbios de vazão.

\section{Conclusões}

Para a metodologia da amostragem utilizada, o CUC e o CUD através da avaliação de campo tiveram valores superiores a $90 \%$ e com isso o sistema foi classificado como excelente, segundo literatura pertinente.

\section{Referências}

BERNARDO, S. Manual de Irrigação. 6.ed. Viçosa: UFV, Imprensa Universitária, 2002. 656p.

BERNARDO, S.; SOARES, A. A.; MANTOVANI, E. C. Manual de Irrigação. $8^{\text {a }}$ Ed. Viçosa, Ed. UFV, 2006, 625p.

Heermann, D.F.; Duke, H.R.; Serafim, A.M.; Dawson, L.L. Distribution functions to represent center-pivot water distribution. Transactions of the ASAE, St. Joseph, v.35, n.5, p.1465-1472, 1992.

KELLER, J.; BLIESNER, R.D. Sprinkle and trickle irrigation. New York: van Nostrand Reinhold, 1990. 652p.

KELLER, J.; KARMELI, D. Trickle irrigation desing. Glendora: Rain Bird Sprinkler Manufacturing, 1975.

KELLER, J.; KARMELI, D. Trickle irrigation design parameters. Transactions of the ASAE, St. Joseph, v. 17, n. 4, p. 678-684, 1974

MATOS, J. A.; DANTAS NETO, J.; AZEVEDO, C. A. V.; AZEVEDO, H. M. Avaliação da distribuição de água de um microaspersor autocompensante. In: Revista Irriga, Botucatu, v.4, n.3, p. 168-174, 1999.

REZENDE. R. Desempenho de um sistema de irrigação pivô central quanto à uniformidade e eficiência de aplicação de água abaixo e acima da superfície do solo. Piracicaba: ESALQ/USP, 1992. 86p. Dissertação. 